\title{
Asymmetric information in subcontracting Received decisions: the effects of the first mover ${ }^{\text {st }}$ August 2019 advantage $^{1}$

\author{
Emanuela Delbufalo - Marina Monsurrò
}

\begin{abstract}
Purpose of the paper: The article analyses, in an adverse selection set-up, the effects of the first mover advantage in subcontracting decision between a manufacturer and a supplier in the situation of asymmetric information.

Methodology: The study proposes a game theory model to analyze a supply chain consisting of a single risk-neutral supplier and a single risk-neutral manufacturer facing a contract definition problem.

Results: The model suggests the strategies to obtain a more convenient arrangement for the manufacturer both in screening and signaling framework.

Research limitations: The empirical examination with real-life data needs to be expanded and performed in a cross-sector context.

Practical implications: The model helps the manufacturer in designing the appropriate arrangement for subcontracting relations and extracting hidden information from the suppliers.

Originality of the paper: Our approach provides a comprehensive quantitative analysis of the effects of the first mover advantage in manufacturer-supplier relationships.
\end{abstract}

Key words: information asymmetry; subcontracting; manufacturer; supplier; signalling; screening

\section{Introduction}

In recent times, factors including competition among companies, growing expectations of customers and products' short life cycle require companies to manage their resources along the supply chain as efficient as possible. Efficiency goals may be met through decisions of cost cutting such as business process reengineering (Aitken et al., 2003) and organizational efforts such as strategic simplification of processes with the aim to focus on firm's core competence (Prahalad and Hamel, 1990). A traditional method to achieve simplification and efficiency of processes is to offload activities, processes and functions to an outside partner by using outsourcing and subcontracting arrangements (Quinn, 1999).

Specifically, subcontracting is the choice of a firm to procure an item or service instead of producing it by using its own resources and facilities.

1 Selected paper from ADACI-SMART Conference 2018, Tivoli Terme, Roma, Italy, November 8-9, 2018 
sinergie Vol. 37, Issue 3, 2019

This choice requires the firm to select the appropriate subcontractor and design a contract that contains all the specifications available to the supplier to perform the required activity (Day, 1956). In making the subcontracting decision, a firm needs to take into account many factors including internal capacity and the cost of in-house production, the characteristics of the suppliers and their production costs per unit. However, asymmetric information and performance ambiguity negatively impact on the search for efficiency in the subcontracting decision (Biong, 2012), as suggested by Arrow (Arrow, 1963, p. 45): "[. . . ] by definition the agent [subcontractor] has been selected for his specialized knowledge and the principal [manufacturer] can never hope to completely check the agent's performance". In such a context, the maximization of the manufacturer's profit is strongly linked to the possibility to extract hidden information concerning the resources and capabilities of the supplier in order to reduce the threat of opportunistic behaviour and increase the efficiency of the subcontracting decision.

In order to solve the asymmetric information problem mentioned above, we propose a game theory model to study a supply chain consisting of a single risk-neutral supplier (or subcontractor) and a single risk-neutral manufacturer facing a contract design problem in the subcontracting decision. The manufacturer doesn't know the exact cost structure of the supplier such as raw material costs, labor costs, and yield of production. Therefore, the supplier's marginal production cost or his type (specialized or not specialized) is only privately known. This naturally leads to an adverse selection model which considers both signalling (Spence, 1973) and screening (Rothschild and Stiglitz, 1976) settings. In the signalling, the informed player (the supplier) benefits from the first mover advantage and takes actions before the manufacturer agrees to a contract while in the screening the order to play is inverted and the manufacturer can benefit from the first mover advantage.

Our model discusses and compares different ways to obtain hidden information - concerning the supplier's ability and quality level (or attributes) of the supply offer - and maximise the manufacturer's expected profit. We analyse the problem from the manufacturer's perspective, also providing reccomendations on the more appropriate actions to uncover the hidden information from the supplier either in the case of the manufacturer doing the first move (screening case) or the supplier's doing an offer at first (signalling case).

The model can be applied to situations where the manufacturer trades with the supplier for the first time: here, the manufacturer may not fully understand the supplier's technology, degree of specialization and workforce profile and thus may not be able to evaluate the supplier's production costs. A supplier with highly flexible resources (e.g., generalpurpose equipment and cross-trained workers) may have a different marginal production costs from one with highly dedicated resources (e.g., specialized equipment and workers). This leads to highly unpredictable situations for the manufacturer, thus increasing the threat of opportunistic behaviour.

The model is also useful to suggest the most appropriate actions for 
the manufacturer to reduce the amount of uncertainty in transactions with well-known suppliers. Here, the set up is endogenous as the partner starting the transacting process is chosen by the nature of the economic exchange and by the bargaining power of the actors. This situation is the most common in traditional manufacturer-supplier relationship where endogenous factors - such as type of supply, firm size, availability of suppliers, market concentration, risk aversion, etc. - determine who has the interest in starting the transaction by sending/offering information or request. Our model provides recommendations for the manufacturer in order to obtain the most efficient subcontracting arrangement, i.e. a separating contract such that each type of supplier signals or is screened effectively. The study also provides an empirical examination of the model with real-life data from the fashion industry in order to show its potential in concrete situations.

\section{Literature review}

The practice of subcontracting is widespread in many industries because of the many advantages this can bring to a firm. When a firm subcontracts out some of its tasks, this allows it to concentrate on its core competence. Subcontracting lowers investment requirements, and thus, the financial risk of the firm. It also helps the firm improve its response to customer demand. Furthermore, if a firm subcontracts an entire operation to a subcontractor, the demand uncertainty of the supply chain is reduced through the risk-pooling effect (Chen and Li, 2008).

A large body of literature discusses the benefits and issues of subcontracting by using a quantitative modelling (Ioannou, 1995). There is a considerable part in literature also dedicated to contract design under the assumption that the parties in the supply chain possess the same information when making their decision (see, for details, Tayur et al., 1999; Cachon, 2005). Here, we limit our analysis to the quantitative research dealing with information sharing and asymmetric information in supplier-manufacturer relationships.

Along this domain, Corbett and Tang (1999) consider optimal contracts in six scenarios. They compare the profits in these different scenarios and examine the value to the supplier of getting better information about the retailer's cost. Biong (2012) examines the relative importance of various signals of supplier reputation conveying information about unobserved supplier quality, which is important for identifying the best tender in service subcontracting. Ha (2001) considers the problem of designing a contract to maximize the supplier's profit in a supplier-buyer subcontracting relationship for a short-life-cycle product. Özer and Raz (2011) propose a model to study the competition between a big and a small supplier over a component supply contract to a downstream manufacturer. They analyze how the optimal two-part tariff offered by the big supplier and the resulting supply chain performance depend on his information about the other player's cost structure. Çakanyildirim et al. (2012) propose a game theory model to analyse contracting and coordination between a supplier and a
Emanuela Delbufalo

Marina Monsurrò

Asymmetric information in

subcontracting decisions:

the effects of the first mover advantage 
retailer under asymmetric production cost information. They suggest that information asymmetry alone does not necessarily induce loss in channel efficiency.

Our adverse selection model is different from the above in two fundamental ways. First, we address the optimal structure of the manufacturer-supplier arrangement in subcontracting decisions considering both the screening and signalling set-up. To the best of our knowledge this approach is novel in operational management literature. Second, we assume the manufacturer maximization profits perspective and compare screening and signalling mechanisms as devices to obtain hidden information concerning the supplier's characteristics. In supply chain management literature this perspective is interesting because the traditional approach in adverse selection modelling is to adopt a fixed frame of information disclosure. Few studies propose a similar approach but with different objectives: for example, Antelo (2009) addresses the information sharing problem in a context of innovation licensing; Kübler et al. (2008) proposes a comparison between screening and signalling in a model grounded in the context of job market and Ben-Shahar and Feldman (2003) combine signalling and screening mechanisms to reach signaling-screening separating equilibrium in mortgage market.

In the following sections, we present a description of the model and the equilibria in two different scenarios (signalling and screening) along with an empirical examination grounded in the fashion industry. The mathematical description of the main functions and the detailed equations will be presented separately - respectively in Appendix 1, 2 and 3 - in order not to weigh down the dissertation.

\section{Model formulation}

We consider a supply chain with a risk-neutral manufacturer and a risk-neutral supplier (or subcontractor). The manufacturer faces a subcontracting decision and makes a single (one-shot) agreement with a supplier for the production of a specific product (or semi-finished product). We assume that both the manufacturer and the supplier are cost and quality sensitive. The supplier's marginal production cost is privately known. The manufacturer only knows that there are two supplier types: low cost (l) or high cost (h). This is the information asymmetry considered herewith.

\subsection{Signalling}

In the Signalling scenario, the informed supplier sends the signal (makes a supply offer) before the manufacturer offers a contract. A signal in game theoretic definition is different from a message because it is not a costless statement, but a costly action. The supplier knows his marginal costs and his degree of specialization and the manufacturer does not, but he observes the signal. The offer made by the supplier has small effect on the supplier's ability of performing the final task but is useful for demonstrating his ability or degree of specialization to the manufacturer. 
We sketch out the game by listing the players, then illustrating the order and structure of the moves and finally by defining the payoffs for every player.

Players: manufacturer (player $A$ ) and supplier (player $B$ ). Nature $(N)$ is, as usual, not a real player because he has no payoffs and his moves are given by a probability distribution.

\section{Order to play:}

1. Nature chooses the type $t$ of player $B$. We suppose that there exist two types of suppliers namely high cost and low-cost suppliers, so we set $t=h$ with probability $\mu$ and $t=l$ with probability $\lambda=1-\mu$. The two categories of suppliers differ by degree of specialization (linked to specialized assets, technology and knowledge) and ability to perform the task;

2. Player $B$ makes a supply offer indicating the characteristics of the supply. We suppose that there exist two possible outcomes: high quality and low quality supply, so $s \in\{s l, s h\}$.

3. Player A offers a contract, $w=w(s)$ (indicating the wage he is willing to pay for a given supply offer s) and fixes the quantity $q$ he is interested in subcontracting out; the final wage $W=W(s, q)$ will depend on the proposed unitary wage and on the quantity required by player $A$;

4. Player B accepts or rejects the contract;

5. The unitary output $o(t, s)$ is a function of the ability of the chosen supplier and of the signal player B chooses to send. As in step 3, the total output also depends on the quantity and is given by the formula $O(t, s, q)=q \cdot o(t, s)$. In this article, we write "expected output" simply as "output" when no confusion arises.

Payoffs: If the contract is accepted, player B's payoff is given by the total wage $W(s, q)$ minus his cost to produce signal $s$ in the fixed quantity $q$ and player $A$ 's payoff is his profit, i.e. the total output $O(t, s, q)$ minus the wage $W(s, q)$. In formulas:

$$
\Pi(B)=W(s, q)-C(t, s, q) \quad \Pi(A)=O(t, s, q)-W(s, q)(1)
$$

If the contract is refused, the payoff for player $B$ is zero. In that case, player $A$ should make the required product in-house; as above, we use the variable $s$ to design the kind of supply offer player $A$ decides to make. The payoff is given by the output they get for the required product minus the cost they have to support for producing directly. In formulas:

$$
\Pi(B)=0 \quad \Pi(A)=O(s, q)-C(A, s, q) .
$$

\subsection{Screening}

Screening models are games of adverse selection with different order to play. Here the manufacturer (player A) has the possibility of proposing
Emanuela Delbufalo
Marina Monsurrò

Asymmetric information in subcontracting decisions: the effects of the first mover advantage 
sinergie Vol. 37, Issue 3, 2019

a contract before the supplier (player B) makes any offer. We describe the game as in section 3.1.

Players: The same as in Signalling game.

Order to play:

1. As in section 3.1;

2. Player $A$ offers a pair of contracts indicating different wages $w(s)$ and $\mathrm{w}^{\prime}(s)$, both only depending on the quality level of the supply offer;

3. Player $B$ accepts one contract and chooses a supply offer $s$ between $\left\{s_{p}\right.$ $s_{h}$ \} or rejects both;

4. As in section 3.1.

Payoffs: If a contract is accepted, player B's payoff is given by the corresponding total wage minus his total cost to produce the required product; player $A$ 's payoff is, as previously seen, the output $O(t, s)$ minus the wage corresponding to the accepted contract. More formally, if the first or the second contract is accepted, we have respectively:

$\Pi(B \mid w$ accepted $)=W(s, q)-C(t, s, q) \quad \Pi(A \mid w$ accepted $)=O(t, s, q)-W(s, q)(3)$

or

$\Pi\left(B \mid w^{\prime}\right.$ accepted $)=W^{\prime}(s, q)-C(t, s, q) \quad \Pi\left(A \mid w^{\prime}\right.$ accepted $)=O(t, s, q)-W^{\prime}(s, q)(4)$

If both contracts are rejected, the payoffs are as in equation (2).

\section{Description of equilibria}

In our adverse selection model, the interplay between the manufacturer and the supplier gives rise to two main categories of equilibria: a Pooling equilibrium and a Separating equilibrium. In a Pooling equilibrium, both types of suppliers (i.e., specialized and not specialized) choose to send the same signal, so that the manufacturer can hardly evaluate the supplier's type. In a Separating equilibrium, conversely, each type of supplier chooses the appropriate signal and the manufacturer obtains complete information.

In the following, we describe the equilibria by listing the set of strategies for both players. We discuss separately the signalling and screening settings, also illustrating how Separating equilibria are in both cases more interesting for the manufacturer. We refer to the Appendix for the definition of the main functions involved and for explicit equations.

\subsection{Signalling}

In the signalling scenario, we can obtain two different Pooling equilibria and a Separating one.

In Pooling equilibrium 1, both types of suppliers chose to send a lowquality supply signal (i.e., a signal stating that they intend to offer a low cost and standardized semi-finished product). As seen before, we are interested in studying the conditions undermining this kind of equilibrium because 
it describes a situation where no information on the type of supplier are available for the manufacturer. This equilibrium results difficult to undermine and unconvenient for the manufacturer as the supplier (either specialized or not) finds more convenient to send a less costly signal regardless his real potentialities and the manufacturer can hardly uncover such event.

The manufacturer has the possibility to undermine the stability of the equilibrium - thus increasing his chance to maximize payoffs - by obtaining credible assurance about the supplier's behaviour and intentions. In fact, the stability of this equilibrium deeply depends on out of equilibrium beliefs: if we suppose that the manufacturer believes in the correspondence between the supplier's signal and the actual supplier ability, then he will be willing to offer a contract (and a wage) corresponding to his beliefs undermining the pooling constraints (see Appendix 2 for explicit equations). One can object that this kind of out of equilibrium beliefs are not conceivable because the idea of a firm believing blindly to a partner is not realistic. However, the hypothesis of repeted interaction with the same supplier reduces the performance ambiguity of the manufacturer-supplier relationship and changes the consequent out of equilibrium beliefs. In fact, when modeling interaction with a consolidated partner (i.e. suppliers having worked with the manufacturer in the past), we can suppose an out of equilibrium belief for the manufacturer marked by a very strong probability that the signal sent by each supplier corresponds to his actual ability and behaviour. This will create new conditions for the updated wage, thus reducing the stability of the equilibrium. To understand better this situation, we will test the model in a real-life case in section 5 .

The second possible equilibrium is a Separating equilibrium where the not specialized supplier makes a low-quality supply offer (i.e., low cost and standardized product) while the specialized supplier makes a high quality one (i.e., high cost and differentiated product). Here, the manufacturer proposes a contract/wage correspondent to the observed signal. In order to make this equilibrium a perfect Bayesian equilibrium, the model considers both the standard participation constraint for the manufacturer and the self-selection constraint for the supplier (stating that neither the not specialized suppliers are tempted to propose a high quality supply nor the specialized a low one) (see Appendix 2 for explicit inequalities). The Separating equilibrium does not need to specify out of equilibrium beliefs since both signals can be observed in equilibrium and Bayes' rule suggests to the manufacturer how to interpret the observed signal. The suppliers are free to deviate from the self-selection constrait above mentioned (we explain in details under what conditions they have no interest in doing so in Appendix 2) but the manufacturer will still believe in equilibrium behavior. Since it does not depend on out of equilibrium beliefs, the stability of this equilibrium does not change in the case of consolidated or new suppliers. As discussed before, a strategy permitting this kind of equilibrium is specially interesting for the manufacturer, not only because of the high payoffs obtained, but because of the possibility of extracting by the supplier's signal full information about his ability and intentions. Besides, this kind of equilibrium allows the manufacturer the development
Emanuela Delbufalo
Marina Monsurrò

Asymmetric information in subcontracting decisions:

the effects of the first mover advantage 
sinergie Vol. 37, Issue 3, 2019

of a differentiated portfolio of suppliers (including both specialized and not specialized partners) to whom he offers a wide set of different contracts corresponding to a complex supply management strategy. It is important to note that, in the Signalling setting, the manufacturer cannot benefit from the first move advantage so the possibility of obtaining such an advantageous situation (complete information and very high payoffs) is particularly convenient.

Finally, we consider Pooling equilibrium 2, where both types of B players choose to send a signal of high-quality supply and the manufacturer pays a fixed wage. As we have seen for the first Pooling equilibrium, this situation is not convenient for the manufacturer. However, in this case the equilibrium stability is not depending on out of equilibrium beliefs (as explained in Appendix 2) and thus in many cases is not sufficiently strong (cfr. Rasmussen, 2006). By understanding correctly, the cost functions considered as common knowledge - the manufacturer can create a situation where the equilibrium can never be Nash and not specialized suppliers will be tempted to deviate from the equilibrium strategy. This situation is more suitable for the manufacturer and increase his payoffs. This will become explicit in the real-life case presented in section 5.

\subsection{Screening}

In the screening scenario the manufacturer has a first move advantage. This situation gives to the manufacturer the possibility of creating a strong Separating equilibrium, maximizing his payoffs and permitting complete information about the ability of the supplier. The manufacturer is able to propose two different contracts which satisfy not only the obvious participation constraint for both players but also a non-pooling constraint; namely, the manufacturer should make the contract offer in such a way that not specialized suppliers always chose the first one and specialized suppliers the second one. Thus, the manufacturer obtains a Separating equilibrium as the only possible one.

It is important to remark that this equilibrium allows the manufacturer to keep both kinds of possible product (low cost/standardized and high cost/differentiated product) in such a way that, in both cases, the expected payoffs are greater than what he will get by producing in-house the required product. In concrete situations, it is plausible that the manufacturer is interested in including both kinds of products in his portfolio and choose between them each time by considering the cost-quality tradeoff. Moreover, the non pooling constraint provides the manufacturer a complete knowledge about the ability of the supplier since no type of supplier is tempted to deviate from the separating equilibrium.

\section{An experimental case in the fashion industry}

For a better understanding of the model, the study considers an experimental case in the fashion industry. The fashion industry seems particularly adequate for the study purposes as in this context the 
subcontracting decisions and suppliers portfolio management are crucial for the competitiveness of manufacturing firms (Cerruti and Delbufalo, 2009). Besides, within this context the effectiveness of subcontracting is linked to the capability of facing the difficult trade-off between minimizing costs and maximizing quality level and thus, the game theory modelling could provide interesting insights and practical contributions.

Traditionally, fashion industry has been characterized by face-to-face mode of governance for subcontracting decisions where the reputation and the history of interaction were considered as main predictors for partners' behaviours. However, the massive process of delocalization and offshoring towards low-cost countries have extended the supply base to a global scale and has changed the governance of subcontracting decisions from relational to more structured (contractual) mechanisms. The geographic and cultural distance between the buyer and the supplier has made relying exclusively on relational mechanism in the transaction more difficult and has stimulated the development of stronger protecting mechanism against potential opportunistic behaviours. Besides, the search for cost savings (which was the main driver for offshoring and global sourcing) has changed the relevance of production cost information in subcontracting contract, giving rise to situations which our theoretical model might depict and explain. Besides, in the fashion industry the asymmetry in bargaining power and the wide supply base make plausible to consider multiple scenarios in which either the buyer or the supplier takes the initiative for starting a transaction, thus making applicable both the screening and signaling set-up.

In order to collect real-life data, a panel of experts with extensive experience in managing supply relationship in the fashion industry has been selected. The panel composition is as follows: 6 respondents from 3 different manufacturing firms, 6 respondents from semi-finished product suppliers and 2 external procurement experts from a fashion districts service association. The nature and purpose of this study was first explained to the panel and comments from the experts were collected using semistructured interviews. Then the panel was asked to provide quantitative data to verify the model. The results of the model application have been revised and commented by the experts.

The data collected refer to a situation in which a manufacturer looks for the best solution to subcontract a production process to a supplier. As seen before, we have two possible kinds of suppliers with different abilities to produce the required product (i.e., specialized and not specialized suppliers). The games are the same described respectively in sections 3.1 and 3.2 (and in an extensive way in Appendix) but here we fix the probability distribution in step 1 by setting $\mu=0.6$. In step 2 we quantify the difference between the two possible offers (signals) by setting $s_{l}=6, s_{h}$ $=7.5$ and, in step 3 , we consider the normalized function of cost and wage in order to be able to set $q^{\prime}=1$. We suppose $q^{\prime}<1$, in order to have a nontrivial function $k=k(\mathrm{q})$, i.e. a substantial impact of scale economy on the cost supported by specialized supplier. In search for simplicity, we suppose the expected quantity to coincide with the real quantity: $E_{q}=q=1$. This assumption is not restrictive, because we can suppose the forecast made by
Emanuela Delbufalo

Marina Monsurrò
Asymmetric information in subcontracting decisions: the effects of the first mover advantage 
sinergie Vol. 37, Issue 3, 201

suppliers good enough; besides, it is frequent in the literature to consider the supplier as a risk neutral player, so the possible difference between $q$ and $E_{q}$ can be ignored without any loss of plausibility. table:

Using the panel data, we can define the cost functions as in the following

Tab. 1: cost functions

\begin{tabular}{|c|c|c|c|}
\hline $\mathrm{C}(\mathrm{t}, \mathrm{s})$ & $\mathrm{t}=\mathrm{h}$ & $\mathrm{t}=\mathrm{l}$ & $\mathrm{A}$ \\
\hline $\mathrm{s}=6$ & 5.8 & 6.25 & 6.4 \\
$\mathrm{~s}=7.5$ & 6.3 & 7.9 & 8 \\
\hline
\end{tabular}

Let us now consider all the possible equilibria.

\subsection{Signalling}

In this situation, Pooling equilibrium 1 is: $s(l)=s(h)=6 ; w=6$, 3. This choice of $w$ clearly satisfies the participation constraint (6) (in Appendix 2).

In order to verify that this is a Perfect Bayesian equilibrium, we have to fix the out of equilibrium beliefs for the manufacturer when he observes $s$ $=7.5$. In passive conjecture, i.e. $\operatorname{Prob}(t=h \mid s=7.5)=\mu=0.6$, when the good signal is observed, the adequate response for the manufacturer is to offer an updated price:

$$
w^{\prime}=7 \cdot \mu+6,3 \cdot(1-\mu)
$$

Such a choice, natural for the manufacturer once considered his estimated payoffs, and then expected by the suppliers, satisfies the bounds (7), (8) and (9) in Appendix 2 and so maintains the equilibrium.

Under different out of equilibrium beliefs, this pooling equilibrium brakes down. As we saw in the general case, if we fix the conjectured probability as $\operatorname{Prob}(t=h \mid s=7.5)=1$, the wage $\mathrm{w}^{\prime}$ - that the suppliers can expect the manufacturer will propose in case he observes signal $s=$ 7.5 - comes up to 7 (by the same reasoning seen before) and specialized suppliers will deviate from equilibrium. Outside this inconceivable situation, the empirical data suggest that, in case of consolidated suppliers (i.e., suppliers with previous interaction with the manufacturer), one can estimate the probability $\operatorname{Prob}(t=h \mid s=7.5)=0.75$ and the updated wage becomes $\mathrm{w}^{\prime}(7.5)=7 \cdot 0.75+6.3 \cdot 0.25=6.825$. This is enough to make the equilibrium not Nash anymore because, with such an expected value of w', the constraint for specialized suppliers (9) (in Appendix 2) is not fulfilled anymore.

The second possible equilibrium is a Separating equilibrium, namely $\mathrm{s}(\mathrm{l})=6, \mathrm{~s}(\mathrm{~h})=7.5$ and $\mathrm{w}(6)=6.3, \mathrm{w}(7.5)=7$. Again, this choice of $w$ satisfies participation constraint for player A in equation (11) in Appendix 2 and self-selection constraint for both types of suppliers, inequalities (13) and (15). As observed in Appendix 2, in the Separating equilibrium we don't need to specify out of equilibrium beliefs, since both signals can be observed, and Bayes' rule tells the manufacturer how to interpret the observed signal.

The last possible equilibrium is Pooling equilibrium 2, i.e. a situation where both types of suppliers choose signal $s=7.5$ and the manufacturer 
pays a fixed wage $w$. Nevertheless, considering the data, this equilibrium can not be Nash because inequalities (16) and (17) in Appendix 2 are inconsistent and no choice of $w$ can satisfy both of them.

\subsection{Screening}

In the screening scenario, the interest of manufacturer is to propose one or many contracts in order to distinguish between specialized and not specialized suppliers. A Separating equilibrium is given by the pair of contracts $w$ and $w$ ' defined by:

$$
w(s)=6,3=\mathrm{w} \text { for any value of } s, w(s)=\left\{\begin{array}{l}
6 \text { if } s=6 \\
7 \text { if } s=7.5
\end{array}\right.
$$

The strategy for suppliers consists in choosing contract $w$ and supply $s=6$ if they are not specialized and contract $w$ with supply $s=7,5$ if they are specialized. Straightforward calculations prove that participation constraint (19) in Appendix 3 is satisfied for this choice of $w$ and w' Concerning the non-pooling constraint, one can confirm that the bounds for not specialized suppliers and for specialized ones are fullfied (see equations 20 and 21 in Appendix 2). This proves that no type of suppliers will be tempted to deviate from Separating equilibrium. As in the case of Signalling, no need here for fixing the out of equilibrium beliefs. We remark that this equilibrium allows the manufacturer to keep both kinds of possible offer (high cost and low cost product) and in both cases the expected payoffs are greater than what he will get by producing in-house the product (using the formulas above 5, 7> 5, 6 and 7, $4>7$ respectively). Besides, the difference between to make and to buy (in term of total payoffs) is greater for $s=7,5$ so that the importance of carefully evaluating supply offers is greater for high cost/differentiated products, as they require more specific investments, resources and specialized knowledge.

\section{Conclusions}

This study combines the signalling and screening set-up to analyse the information asymmetry problem in subcontracting arrangements. Specifically, the adverse selection model compares the different strategies for the manufacturer to obtain hidden information (concerning the supplier's ability) and maximise his expected payoffs in screening and signaling set up.

The model and the empirical analysis suggest that, in situations in which the supplier benefits from the first move advantage and takes the initiative to start a transaction by presenting an offer to the manufacturer (i.e., signalling scenario), the risk to obtain a Pooling equilibrium is higher than in the screening scenario. A pooling equilibrium is less convenient for the manufacturer than Separating equilibrium - also possible in such a situation - because here the information asymmetry still exists, and the manufacturer has no credible assurance about the intention and ability of the supplier. In order to undermine the pooling equilibrium
Emanuela Delbufalo Marina Monsurrò Asymmetric information in subcontracting decisions: the effects of the first mover advantage 
sinergie Vol. 37, Issue 3, 2019

when it appears, the manufacturer needs to collect details about the past behaviour of the potential suppliers by using relational mechanisms such as reputation or past experience. Obtaining such information increases the transaction costs and the supply risks. As suggested in management literature, when economic interaction is based on observing the other player's actions and responding to them, performance and relational ambiguity can make subcontracting decisions more difficult (Poppo et al., 2008). Our model suggests that leaving to the supplier the initiative to start the transaction might increase the performance and relational ambiguity for the manufacturer, with negative returns on the economic exchange. This negative effect (linked to the stability of Pooling equilibria) is reduced in situations of repeated interaction between a manufacturer and a supplier: such repeated interactions can disclose the real capabilities of the supplier, despite the signals he decides to send. The benefits linked to repeated interaction with consolidated suppliers - here pictured in the out of equilibrium beliefs - are well known in management literature and widely recognized as essential for the effectiveness of subcontracting decisions (e.g., Biong, 2012). Nevertheless, we remark that such a low performance ambiguity is not achivable in any supply chain situations so that Pooling equilibria should be included in the model and taken into account for a complete analysis of the problem. In fact, there is a wide empirical evidence for situations in which the suppliers are encouraged to start the transaction by sending an offer to the manufacturer (see, for example, the tendency to use bidding procedure for suppliers' selection). Our model discourages such arrangement as it increases the performance ambiguity and the transaction costs for the manufacturer. Only in case of known suppliers, this suppliers' selection strategy (this doesn't make sense) the manufacturer is able to undermine the stability of the Pooling equilibria (i.e., less convenient outcome) and obtain the expected payoffs from the transaction.

On the contrary, when the manufacturer can experience the first move advantage (screening framework), the menu of contracts offered can be designed in such a way that both specialized and not specialized suppliers won't be tempted to deviate from the Separating equilibrium (which is the most convenient for the manufacturer). In this context is possible, under suitable conditions on the concerned functions, to settle a non pooling constraint. The opportunity for the manufacturer to obtain a high cost and differentiated semi-finished product from specialized suppliers and a low cost and strandardized semi-finished product from not specialized suppliers is the main benefit of this situation. This opportunity is also a primary objective for the manufacturer in order to optimize the supply portfolio management and obtain the higher results (in terms of expected payoffs) from the subcontracting decisions. Moreover, the non pooling constraint provides the manufacturer a complete knowledge about the suppliers' ability, thus providing inherently a solution for the asymmetric information problem.

It is also important to remark that the Separating equilibrium allows the manufacturer to keep both kinds of possible outputs (i.e., standardized and differentiated semi-finished products) in such a way that in both cases 
the expected payoffs are greater than what he will get by producing inhouse the required products. In concrete situations, it is plausible that the manufacturer is interested in including both kinds of alternatives in its portfolio and chooses between them each time by considering the cost-quality trade-off. Literature and the empirical evidences reported in section 5 support these results and suggest that this is the case with regards to the fashion industry. In fact, the wide variety of fashion outputs - in terms of design and quality attributes - are consistent with the presence of multiple suppliers with different degrees of specialization/ability into the manufacturers' portfolio. Here, the main critical task for the fashion manufacturer is to integrate subcontractors with different abilities into a balanced portfolio as well as to optimise their engagement by considering (and clearly detecting) their specific resources and capabilities (Tran, 2010). Our model suggests the manufacturer to reduce the performance ambiguity by starting tha transaction with the suppliers. The first mover advantage is beneficial not only because it reduces the threat for opportunistic behaviours but also because it allows the distinction between different typologies of suppliers - which is more difficult to obtain when in the signaling set-up.

\section{Implications and limitations}

From a theoretical perspective, our adverse selection model contributes to the literature in two ways. Firstly, the model formulation comparing the screening and signalling set-up provides a novel contribution to the operational management literature, mostly adopting a fixed frame of information disclosure. Secondly, we suggested the most efficient way for the manufacturer to obtain hidden information concerning the supplier's characteristics by analyzing the effects of the first mover advantage of both actors. In supply chain management literature this perspective is interesting because - with only few exceptions (e.g., Antelo, 2009; Kübler et al., 2008) the decision to start a transaction is generally considered exogenous.

From a managerial point of view, this study can be useful in two different ways. Firstly, it confirms that the screening situation - where the manufacturer can experience a first move advantage - is the more favourable one in order to maximize the manufacturer's profit in subcontracting decisions: here, the manufacturer has the chance to design contracts aligned with the real abilities of the suppliers without the need to invest in costly and time-consuming activities to disclose the suppliers' behaviours. However, the market conditions and/or the bargaining power of the manufacturer not always allow the set up of a creening scenario where the manufacturer starts the negotiation and the suppliers react to a stimulus sent to them. As in the case of fashion industry where the supply market is highly concentrated, it is not uncommon that a subcontracting relationship starts from the suppliers' offering. Here, the risk of establishing not convenient equilibria for the manufacturer is higher and the investment in information disclosing mechanisms is more urgent. Secondly, the study confirms the value of repeated interactions
Emanuela Delbufalo Marina Monsurrò Asymmetric information in subcontracting decisions: the effects of the first mover advantage 
sinergie Vol. 37, Issue 3, 2019

in manufacturer-supplier relationships. Repeated interactions, reducing the performance and relational ambiguity in the economic exchange, change the out of equilibrium beliefs and increase the chance to obtain a convenient outcome for the manufacturer. Repeated interactions are mostly useful when both specialized and not specialized suppliers decide to send the same (low quality) signal to the manufacturer. In this case, when the specialized supplier decides to hide his real ability - in order, for example, to protect his knowledge by misappropriation - the formation of Pooling equilibrium 1 creates the most inconvenient scenario for the manufacturer. The only possibility to undermine such negative outcome is to use/collect information concerning the supplier's behaviour in previous interactions which unveil the real suppliers' abilities and allow the manufacturer to respond with appropriated and differentiated contracts to the suppliers' signal.

This study has limitations. Firstly, we've analysed the problem of information asymmetry from the manufacturer's perspective, also providing reccomendations on the more appropriate actions for this single actor of the transaction. A more balanced perspective which takes into account also the supplier's perspective (and convenience) might increase the theoretical and practical contribution of the analysis. Secondly, the model formulation considers a supply chain with a risk-neutral manufacturer and a risk-neutral supplier. This might not be the case in every supply chain context, where both the manufacturer and the supplier may be risk averse due to different sizes and context of analysis (Antelo, 2009). Third, the experimental case in the fashion industry has limited external validity due to the small sample size and the single-transaction perspective. In fact, by considering a situation in which the manufacturer makes a single (oneshot) agreement with a supplier, we restrict the analysis and loose the possibility to consider the effects of multiple games (agreements) between the two actors. Future research could expand this perspective and extend out model to repeated exchange situations. In addition, a longitudinal experiment with a larger sample could increase the study's external validity and provide more arguments for discussion.

\section{References}

AITKEN J., CHILDERHOUSE P., TOWILL D. (2003), “The impact of product life cycle on supply chain strategy", International Journal of Production Economics, vol. 85, n. 2, pp. 127-140.

ANTELO M. (2009), The dominance of fee licensing contracts under asymmetric information and signalling, Working Paper E2009/08, CentrA

ARROW K.J. (1963), Social Choice and Individual Values, Yale University Press, New Haven, CT.

BANKS J. (1991), Signalling Games in political Sciences, Harwood Publishers, Chur, Switzerland.

BEN-SHAHAR D., FELDMAN D. (2003), "Signaling-screening equilibrium in the Mortgage Market", Journal of Real Estate Finance and Economics, vol. 26, n. 2/3, pp. 157-178. 
BIONG H. (2012), "Choice of subcontractor in markets with asymmetric information: reputation and price effects", Journal of Business and Industrial Marketing, vol. 28, n. 1, pp. 60 - 71

CACHON G. (2005), "Supply chain coordination with contracts", Graves S. T. Kok, eds. Handbooks in OR. North Holland, Amsterdam, pp. 229-340.

ÇAKANYILDIRIM M., FENG Q., GAN X., SETHI S.P. (2012), “Contracting and coordination under asymmetric production cost information", Production and Operations Management, vol. 21, n. 2, pp. 345-360.

CERRUTI C., DELBUFALO E., (2009), "International sourcing effectiveness in the fashion industry: the experience of Italian industrial districts", International Journal of Globalisation and Small Business, vol. 3, n. 4, pp. 427-440.

CHEN Z.L., LI C.L. (2008), "Scheduling with subcontracting options", IIE Transactions, vol. 40, n. 2, pp. 1171-1184

CORBETT C., TANG C. (1999), "Designing supply contracts: Contract type and information asymmetry”, Tayur R.G., Magazine S.M., eds. Quantitative Models for Supply Chain Management, Kluwer Academic Publishers, Boston.

DAY J.S. (1956), Subcontracting policy in the airframe industry, Graduate School of Business Administration, Harvard University, Boston, MA.

HA A.Y. (2001), "Supplier-buyer contracting: Asymmetric cost information and the cut-off level policy for buyer participation", Naval Res. Logist. vol.1, n. 48, pp. 41-64.

IOANNOU L. (1995), "Subcontracting's subtle subversions", International Business, June 1995, pp. 20-22.

JULLIEN B. ( 2000), "Participation constraints in adverse selection models", J. Econ. Theory, vol.2, n. 93, pp. 1-47.

KÜBLER D., MÜLLER W., NORMANN H.T. (2008), "Job-market signalling and screening: an experimental comparison", Games and Economic Behavior, vol.1, n. 64, pp. 219-236.

LUTZE H.S., ÖZER Ö. (2008), "Promised leadtime contracts and renegotiation incentives under asymmetric information”, Oper. Res., vol. 56, n. 8, pp. 898-915.

ÖZER Ö., RAZ G. (2011), "Supply chain sourcing under asymmetric information”, Prod. Oper. Manag., vol. 20, n. 1, pp. 92-115.

PITTAWAY L., ROBERTSON M., MUNIR K., DENYER D., NEELY A. (2004), "Networking and innovation: a systematic review of the evidence", International Journal of Management Reviews, vol. 5/6, n. 3-4, pp. 137-168.

POPPO L., ZHOU K.Z., ZENGER T.R., (2008), "Examining the conditional limits of relational governance: specialized assets, performance ambiguity, and longstanding ties", Journal of Management Studies, vol. 45, n. 7, pp. 1195-1216.

PRAHALAD C., HAMEL G. (1990), "The core competence of the corporation", Harvard Business Review, vol. 68, n. 3, pp. 79-91.

QUINN J.B. (1999), "Strategic outsourcing: Leveraging knowledge capabilities", Sloan Management Review, vol. 40, n. 4, pp. 9-22.

RASMUSSENN E. (2006), Games and Information. An Introduction to Game Theory ( $4^{\text {th }}$ Revised edition), Blackwell Publishing Ltd, Oxford, UK.

ROTHSCHILD M., STIGLITZ J. (1976), "Equilibrium in competitive insurance market: an essay in the economics of imperfect information", Quarterly Journal of Economics, vol.4, n. 90, pp. 629-649.
Emanuela Delbufalo

Marina Monsurrò

Asymmetric information in

subcontracting decisions:

the effects of the first mover advantage 


\section{sinergie}

Vol. 37, Issue 3, 201

SPENCE A.M. (1973), Market signalling: information transfer in hiring and related processes, Cambridge, MA: Harvard University Press.

STATEN M., UMBECK J. (1986), "A Study of Signaling Behavior in Occupational Disease Claims", Journal of Law and Economics, vol. 29, n. 2, pp. 263-286.

TAYUR S., GANESHAN R., MAGAZINE M. (1999), Quantitative models for Supply Chain Management, Kluwer Academic Publishers

TRAN Y. (2010), "Generating stylistic innovation: a process perspective”, Industry and Innovation, vol. 17, n. 2, pp. 131-161.

\section{Appendix A1: Definition of the main functions}

Let us now define particularly the functions introduced above. The marginal cost supported by player B is a function of his type and of the signal he chooses to send (i.e., it depends on the quality level of the product he proposes to player $A$ ). Even when the difference between the two types of suppliers concerning the marginal cost is not relevant, for increasing values of $q$ the ability of $B$ to perform the task influences his costs because of the influence of the economies of scale. We consider the effect of the economies of scale in order to account for the different degree of specialization of the suppliers. In formulas, the total cost for any type of $B$ player is given by:

$$
C(t, s, q)=q \cdot c(t, s) \cdot K(t, q) .
$$

Here $c(t, s)$ denotes the marginal production cost, only depending on the type of the player and on the quality of the product he decides to offer and $K(q, t)$ is a function of the type of the supplier and of the required quantity, with values in $(0$, $1]$, taking into account the nature of scale economies. For suppliers of low-cost type and for the player $A$, this function can be supposed to be constant and equal to 1 because they lack specific resources and have no possibility to benefit from economies of scale. On the contrary, for suppliers of high cost type it is convenient to increase the quantity as they have got specialized resources to manage this situation and can experience a reduction of the average production costs when the quantity increases. This situation is described by a function where $k(q)$ is a decreasing function with values in $(0,1]$ and q' is a threshold value of $q$ after which scale economy is appreciable. As a consequence, the same signal, especially for increasing quantities, is more costly for a low-cost player than for a high cost one. This difference in signalling costs is called single-crossing property (Rasmussen, 2006).

$$
K(h, q)=\left\{\begin{array}{l}
1 \text { if } q<q^{\prime} \\
k(q) \text { if } q \geq q^{\prime}
\end{array}\right.
$$

The marginal production cost $c(A, s)$ supported by player A for making inhouse a s-kind product is also dependent on the quality level of the output he decides to produce. As explained above, we can suppose that the total cost for player $A$ is then given by the formula

$$
C(A, s, q)=c(A, s) \cdot q
$$

For the unitary output, an explicit formula can be expressed by 
where $s_{t}$ is defined by

$$
o(t, s)=s+\min \left\{s, s_{t}\right\}
$$

$$
s t=\left\{\begin{array}{l}
s_{l} \text { if } t=l \\
s_{h} \text { if } t=h
\end{array}\right.
$$

Emanuela Delbufalo

Marina Monsurrò

Asymmetric information in

subcontracting decisions:

the effects of the first mover advantage

This formula is obtained by adapting usual expressions for the output (e.g., Banks, 1991; Staten and Umbeck, 1986) to the situation we are modeling.

Under this assumption, the best possible output is obtained in the case of a supplier of high type submitting a supplying offer of high quality and the worst one in the case of a low-level offer. In fact, a low type $B$ player cannot produce the best possible output in any case (because of the lack of specialized resources), and a low-quality supply offer produces the worst possible output regardless of the type of the supplier.

Concerning the total wage $W$, player $A$ estimates that the amount to pay should be proportional to the ability (in our case, the specialization) of the supplier and to the quality level of the supply offer. Nevertheless, in both games, the wage must be only function of the signal and cannot depend on the ability, ignored by player $A$. We calculate by probabilistic reasoning the appropriate wages included in the contracts.

\section{Appendix 2: Equilibria in the signaling case}

Suppose first that both types of suppliers chose to send a low-quality supply signal $\left(s=s_{l}\right)$ and that player $A$ pays a constant unitary wage $w$. Pooling equilibrium 1 is:

$$
s(l)=s(h)=s_{l} \quad w(s)=w
$$

To obtain the participation constraint for player A, we compare equations (1) and (2) in section 3.1; by replacing the explicit functions introduced above, we obtain the following bound for the unitary wage w:

$$
w \leq c\left(A, s_{l}\right)
$$

This Pooling equilibrium needs to be specified as a perfect Bayesian equilibrium because of the importance of the interpretation that the uninformed player puts on out of equilibrium behaviour. In our case, we need to specify player $A$ 's beliefs when he observes $s=s_{h}$.

In a situation of passive conjecture, namely $\operatorname{Prob}\left(t=h \mid s=s_{h}\right)=\mu$ (the probability of having a supplier of type $h$, as settled in 3.1), if the good signal is observed, player $A$ will offer an updated wage $w^{\prime}>w$. To understand which choice of $w^{\prime}$ represents an equilibrium response for $A$, we compare the expected payoffs, calculated as the average of the possible payoffs weighted by the probability of facing a high cost or a low cost B player, with the situation of in-house production. In formulas:

$$
\begin{aligned}
& \Pi\left(A \mid w^{\prime} \text { accepted }\right)=\left[s_{h}+\left(\mu \cdot s_{h}+(1-\mu) \cdot s_{l}\right)-w^{\prime}\right] \cdot q \\
& \Pi\left(\mathrm{A} \mid w^{\prime} \text { refused }\right)=\left[2 s_{h}-c\left(A, s_{h}\right)\right] \cdot q .
\end{aligned}
$$

From those equation we derive the following condition on $w$ : 


\section{sinergie}

Vol. 37, Issue 3, 2019

$$
w^{\prime} \leq c\left(A, s_{h}\right)-\left(s_{h}-s_{l}\right)(1-\mu) .
$$

Finally, for Pooling equilibrium 1 to be Nash, $B$ players, regardless to their type, should realize that making an offer of good type is useless so that no one will deviate from the equilibrium position and both choose a signal $s=s_{l}$. In formulas, we want the following inequalities to be fulfilled:

$$
0 \leq \Pi\left(B \mid s=s_{l}\right) \geq \Pi\left(B \mid s=s_{h}\right) .
$$

For low $\operatorname{cost} B$ players, the analysis is easier, and we derive the following bounds on $w$ and $w^{\prime}$ :

$$
w \geq c\left(l, s_{l}\right) \quad \mathrm{w}^{\prime}-w \leq c\left(l, s_{h}\right)-c\left(l, s_{l}\right) .
$$

For specialized suppliers, we introduce the estimated quantity $E_{q}$ i.e., the quantity that a supplier of this type supposes the manufacturer will require in the moment he makes the offer. This can change significantly his attitude because the cost he will support (and hence his estimated payoff) will vary with this quantity. Clearly, if $E_{q}<$ q', the equations are very similar to the previous case, while, in the general case, the equations become

$$
0 \leq w \cdot E_{q}-c\left(h, s_{l}\right) \cdot E_{q} \cdot k\left(E_{q}\right) \geq w \cdot E_{q}-c\left(h, s_{h}\right) \cdot E_{q} \cdot k\left(E_{q}\right) .
$$

We derive the following bounds for $w$ and $\mathrm{w}^{\prime}$ :

$$
w \geq c\left(h, s_{l}\right) \cdot k\left(E_{q}\right) \quad w^{\prime}-w \leq\left[c\left(h, s_{h}\right)-c\left(h, s_{l}\right)\right] \cdot k\left(E_{q}\right) .
$$

As seen before, we are interested in studying the conditions undermining this kind of equilibrium because it describes a situation where no information on the type of player $B$ are available for the manufacturer. As a consequence of formula (7), the stability of the equilibrium deeply depends on out of equilibrium beliefs, represented here by $\operatorname{Prob}\left(t=h \mid s=\mathrm{s}_{\mathrm{h}}\right)$. Clearly, if we suppose that player $A$ believes every supplier presenting a good offer is of type $h$ (i.e. $\operatorname{Prob}\left(t=h \mid s=s_{h}\right)=1$ ), then he will pay an updated wage $w^{\prime \prime}>w^{\prime}$ corresponding to his beliefs that will hardly satisfy inequalities (8) and (9). One can object that this out of equilibrium beliefs are not conceivable because the idea of a firm believing blindly to a partner is not realistic. Nevertheless, when modeling interaction with a consolidated partner, we can suppose an out of equilibrium belief for player $A$ given by $\operatorname{Prob}\left(t=h \mid s=\mathrm{s}_{\mathrm{h}}\right)=\mu$ ' $>\mu$. This will create new conditions for the updated wage and so different stability for the equilibrium. To understand better this situation, we will test the model in a concrete case in section 5 .

The second possible equilibrium is a Separating equilibrium. In this case the low-cost $B$ player will make a low-quality supply offer and the high cost a high quality one. Player $A$ will propose a price based on the signal he observes. So Separating equilibrium is

$$
s(t)=\left\{\begin{array}{l}
s_{l} \text { if } t=l \\
s_{h} \text { if } t=h
\end{array} \quad \text { and } w(s)=\left\{\begin{array}{l}
w \text { if } s=s_{l} \\
w^{\prime} \text { if } s=s_{h}
\end{array}\right.\right.
$$

To obtain a perfect Bayesian equilibrium we check the standard constraints such an equilibrium must satisfy, i.e., the participation constraint for player A and 
a self-selection constraint stating that neither the low cost supplier are tempted to propose a high quality supply nor the high cost a low one.

First, we consider the participation constraint. In the inequalities below, we establish that the expected payoff of player A, regardless to the level of the supply offer, is strictly greater when the proposed contract is accepted than when the selected product is produced in-house. Explicitly:

$$
\begin{aligned}
& \Pi(A \mid w \text { accepted }) \geq \Pi(A \mid w \text { refused }) \\
& \Pi\left(A \mid w^{\prime} \text { accepted }\right) \geq \Pi\left(A \mid w^{\prime} \text { refused }\right)
\end{aligned}
$$

By explicit calculations, the expected payoffs for A, if any contract is accepted, are given by the following table:

Tab. 1: Player A's estimated payoffs

\begin{tabular}{|l|l|l|}
\hline & $s=s_{h}$ & $s=s_{l}$ \\
\hline$w$ & {$\left[s_{h}+\left(\mu s_{h}+(1-\mu) s_{s}\right)-w\right] q$} & {$\left[2 s_{l}-w\right] q$} \\
\hline$w^{\prime}$ & {$\left[s_{h}+\left(\mu s_{h}+(1-\mu) s_{l}\right)-w^{\prime}\right] q$} & {$\left[2 s_{l}-w^{\prime}\right] q$} \\
\hline
\end{tabular}

By comparing this with the in-house payoffs of A expressed in formula (2), we derive the following conditions for $w$ and w':

$$
w \leq c\left(A, s_{l}\right) \quad w^{!} \leq c\left(A, s_{h}\right)-\left(s_{h}-s_{l}\right)(1-\mu)
$$

The constraint for low cost B player is that the payoff obtained by choosing contract $w$ and giving a low quality signal should be positive (participation constraint) and greather than the payoff corresponding to the high quality signal or to the choice of contract w' (self-selection constraint). In formulas:

$$
0 \leq \Pi\left(B \mid w \text { accepted, } t=l, s=s_{l}\right) \geq\left\{\begin{array}{l}
\Pi\left(B \mid w \text { accepted, } t=l, s=s_{h}\right) \\
\Pi\left(B \mid w^{\prime} \text { accepted, } t=l, s=s_{h}\right) \\
\Pi\left(B \mid w^{\prime} \text { accepted, } t=l, s=s_{l}\right)
\end{array}\right.
$$

Here again we derive the conditions:

$$
w \geq c\left(l, s_{l}\right) \quad \mathrm{w}^{\prime}-w \leq c\left(l, s_{h}\right)-c\left(l, s_{l}\right) .
$$

The self-selection constraint for the high cost B player is that the payoff they obtain by giving high quality signal should be grather or equal than payoffs obtained with low quality signal; in formulas:

$$
0 \leq \Pi\left(B \mid w^{\prime} \text { accepted, } t=h, s=s_{h}\right) \geq\left\{\begin{array}{l}
\Pi\left(B \mid w \text { accepted, } t=h, s=s_{h}\right) \\
\Pi\left(B \mid w \text { accepted, } t=h, s=s_{l}\right) \\
\Pi\left(B \mid w^{\prime} \text { accepted, } t=h, s=s_{l}\right)
\end{array}\right.
$$

As before, we have to take into account the estimated quantity Eq, and the bounds on $w$ and $\mathrm{w}$ ! become:

$$
w^{\prime} \geq c\left(h, s_{h}\right) \cdot k\left(E_{q}\right) \quad w^{\prime}-w \geq\left[c\left(h, s_{h}\right)-c\left(h, s_{l}\right)\right] \cdot k\left(E_{q}\right) .
$$

Emanuela Delbufalo Marina Monsurrò
Asymmetric information in subcontracting decisions: the effects of the first mover advantage 
Sinergie Vol. 37, Issue 3, 2019

The Separating equilibrium does not need to specify out of equilibrium beliefs. Since both signals can be observed in equilibrium, Bayes' rule suggests to player $A$ how to interpret the observed signal. Players $B$ are free to deviate (we saw under what conditions they have no interest in doing so) but the manufacturer will still believe in equilibrium behavior. Since it does not depend on out of equilibrium beliefs, the stability of this equilibrium does not change in the case of consolidated or new partners.

As discussed before, a strategy permitting this kind of equilibrium is specially interesting for the player A, not only because of the high payoffs obtained, but because of the possibility of extracting by the player B's signal full information about his type.

Finally, we consider the second possible Pooling equilibrium. In Pooling equilibrium 2 both types of $B$ players choose a signal $s=s_{h}$ and the manufacturer $A$ pays a fixed wage w.

As in Pooling equilibrium 1, participation constraint for player $A$ is given by:

$$
w \leq c\left(A, s_{h}\right)-(1-\mu)\left(s_{h}-s_{l}\right) .
$$

The stability of Pooling equilibrium 2 as perfect Bayesian equilibrium does not depend on out of equilibrium beliefs; in fact, when the bad signal is observed, the output does not depend on the type of player $B$ (see equation (5)); the equilibrium response for $A$, regardless to his out of equilibrium beliefs, is to offer a wage w', only satisfying equation (6).

Concerning $B$ players, in equilibrium, both types should realise that making a low-quality supply offer is not in their own interest so that no one deviates from the equilibrium position and both continue choosing $s=s_{h}$. By computing and comparing the payoffs as before we obtain the bounds for not specialized $B$ players,

$$
w \geq c\left(l, s_{h}\right) \quad w-w^{\prime} \geq c\left(l, s_{h}\right)-c\left(l, s_{l}\right) .
$$

and, respectively, the bounds for specialized B players (taking into account the estimated quantity $E_{q}$ )

$$
w \geq c\left(h, s_{h}\right) \cdot k\left(E_{q}\right) \quad w-w^{\prime} \geq\left[c\left(h, s_{h}\right)-c\left(h, s_{p}\right)\right] \cdot k\left(E_{q}\right) .
$$

The stability of Pooling equilibrium 2 is in many cases not very strong (cf. Rasmussen 2006). In all the situations where the cost functions, considered as common knowledge, make inequalities (16), (6) and (17) inconsistent with each other, this equilibrium can never be Nash because low cost B players are tempted to deviate from the equilibrium strategy. This will become explicit in the case studied in section 5 .

\section{Appendix 3: Equilibria in the screening case}

In this case, the strategy of player $\mathrm{A}$ is to use the first move advantage to create a strong Separating equilibrium. Let us consider in detail the conditions a pair of contracts should satisfy for supporting such a Separating equilibrium. As in the previous subsection, the strategy for player A consists in proposing a pair of wage functions $\left(w(s), w^{\prime}(s)\right)$ and a quantity $q$ and the strategy for player $B$ in choosing the contract $w$ and the supply $s=s l$ if not specialized and the contract $w$ with supply $s$ $=s_{h}$ if specialized. 
The participation constraints for player $A$ are given by formula (10) and, using Table 1, we derive: $w\left(s_{l}\right), w^{\prime}\left(s_{l}\right) \leq c\left(A, s_{l}\right)$

$$
w\left(s_{h}\right), w^{\prime}\left(s_{h}\right) \leq c\left(A, s_{h}\right)-\left(s_{h}-s_{l}\right)(1-\mu) .
$$

Considering now the non-pooling constraint for not specialized suppliers, using inequalities (12), we derive the conditions:

$$
w\left(s_{l}\right) \geq\left\{\begin{array} { r r r } 
{ ( c ( l , s _ { l } ) } & { \text { and } w ( s _ { h } ) } & { - w ( s _ { l } ) } \\
{ w ^ { \prime } ( s _ { l } ) } & { w ^ { \prime } ( s _ { h } ) } & { - w ^ { \prime } ( s _ { l } ) }
\end{array} \left\{\begin{array}{l}
\leq c\left(l, s_{h}\right)-c\left(l, s_{l}\right) .
\end{array}\right.\right.
$$

For high cost suppliers, in analogy with the Signalling case, the conditions depend also on the quantity but, in this case, we do not consider the expected quantity because player $A$ starts the game by choosing the pair $\left(w, w^{\prime}\right)$ and fixing the quantity $q$ that, consequently, is known to player B. In this case the inequalities (14) give the following bounds:

$$
w^{\prime}\left(s_{h}\right) \geq\left\{\begin{array}{l}
\left(k(q) \cdot c\left(h, s_{h}\right) \text { and } w\left(s_{h}\right)\right. \\
w^{\prime}\left(s_{l}\right)+k(q)\left[c\left(h, s_{h}\right)-c\left(h, s_{l}\right)\right] \\
w\left(s_{l}\right)+k(q)\left[c\left(h, s_{h}\right)-c\left(h, s_{l}\right)\right]
\end{array}\right.
$$

If boundaries (20) and (21) are fulfilled, no type of B player will be tempted to deviate from the Separating equilibrium. As in the case of Signalling, there's no need for fixing the out of equilibrium beliefs because both messages $s=s_{h}$ and $s=$ $s_{l}$ can be observed and Bayes' rule permits to establish the estimated payoffs in any case.

\section{Academic or professional position and contacts}

\section{Emanuela Delbufalo}

Associate Professor of Operations Management

European University of Rome

e-mail: emanuela.delbufalo@unier.it

\section{Marina Monsurrò}

Associate Professor of Algebra

European University of Rome

e-mail: marina.monsurro@unier.it
Emanuela Delbufalo Marina Monsurrò Asymmetric information in subcontracting decisions: the effects of the first mover advantage 